Original Article

\title{
Knowledge attitude and practices of oral and personal hygiene to prevent communicable diseases among students in and around the city of Mangalore. An epidemiological survey
}

\author{
Amitha M. Hegde ${ }^{1}$, Adrija Kar ${ }^{2}$, Lekshmi R. $^{3}$ \& Minu Mathew ${ }^{4}$ \\ ${ }^{1}$ Senior Professor and HOD, ${ }^{2,3,4}$ Post Graduate Student, Department of Pedodontics and Preventive Dentistry, A.B. Shetty \\ Memorial Institute of Dental Sciences, M angalore \\ *Corresponding Author : Amitha M. Hegde, Senior Professor and HOD, Department Of Pedodontics and Preventive Dentistry, A B Shetty \\ M emorial Institute of Dental Sciences, M angalore. E-mail : dradrijakar@gmail.com
}

Received : 30-09-2015

Review Completed : 23-01-2016

Accepted

: 14-04-2016

Keywords : personal hygiene, oral hygiene, school health education, communicable diseases.

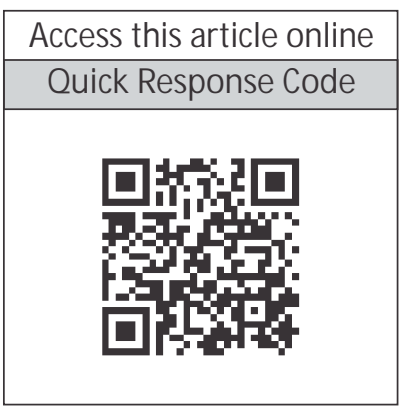

\begin{abstract}
:
Introduction : India is undergoing an epidemiologic, demo-graphic and health transition. The expectancy of life has increased, with consequent rise in degenerative diseases of aging and lifestyles. Nevertheless, communicable diseases are still dominant and constitute major public health issues. There are several factors associated with the control of communicable diseases, such as hygiene, sanitation and safe drinking water, which are interlinked. Inadequate sanitary conditions and poor hygiene practices play major roles in the increased burden of communicable diseases.
\end{abstract}

Objectives : The objectives of this study were to evaluate the knowledge about communicable diseases and practices of proper hygiene measures, among school going children in and around Mangalore, Karnataka.

Methodology : A survey was conducted among the students of an English and Kannada medium school using a basic questionnaire.

Results : An overall lower percentile scores were obtained by children from Kannada medium school.

Conclusion : There is a definite need for intense campaigns for the promotion of good oral and personal hygiene practices better aimed at the prevention of communicable diseases in local regional language medium schools in India.

\section{Introduction}

India is undergoing an epidemiologic, demo-graphic and health transition. The expectancy of life has increased, with consequent rise in degenerative diseases of aging and lifestyles. Nevertheless, communicable diseases are still dominant and constitute major public health issues. A large fraction of the world's illness and death is attributable to communicable diseases. This trend is especially notable in developing countries where acute respiratory and intestinal infections are the primary causes of morbidity and mortality among young children. Since many communicable diseases are transmitted through contact or droplet, performing hand hygiene properly and maintaining respiratory hygiene are two prerequisites for the prevention of such diseases. There are several factors associated with the control of communicable diseases, such as hygiene, sanitation and safe drinking water, which are interlinked. Inadequate sanitary conditions and poor hygiene practices play major roles in the increased burden of communicable disease within these developing countries. WHO data suggests that approximately $3.1 \%$ of deaths (1.7 million) and $3.7 \%$ of disability-adjusted-life years (DALYS) (54.2 million) world-wide are attributable to unsafe water, sanitation, and hygiene (WHO 2002 World Health Report). Of these, over $99.8 \%$ occur in developing countries, and $90 \%$ are of children. Lack of resources, namely soap and water, as well as inadequate sanitation facilities may be two of the main reasons why children fail to maintain proper hygiene. In addition to this, hygiene practices are heavily influenced by students' knowledge 
and attitudes towards hygiene. Past reviews about personal hygiene indicate that perception strongly influences one's hand washing beliefs and practices. Previous studies conducted provide limited details about the practice of hygiene among populations in rural areas and their knowledge about communicable diseases. The objectives of this study were to evaluate the knowledge about communicable diseases and practices of proper hygiene measures, among school going children in and around M angalore, Karnataka.

\section{Methodology}

A survey was conducted among the students of an English and Kannada medium school from classes $3^{\text {rd }}$ to $7^{\text {th }} .602$ children from the English medium and 276 children from the Kannada medium had participated in the study. A basic questionnaire was distributed among all the students and their response to each question was assessed to evaluate their knowledge, attitudes and practices of personal hygiene. Scores were given according to the answers in the questionnaires, such that every correct answer wasscored. The questionnaire along with scores and percentage of children scoring in each were as listed below in table 1 . The maximum score that could be obtained by a child was 28 .

Table: 1

\begin{tabular}{|c|c|c|}
\hline Question & Right (1) & Wrong (0) \\
\hline \multicolumn{3}{|l|}{ To assess the knowledge of students } \\
\hline 1. Do you know that diseases can spread from one person to another? & Yes (83.17\%) & No $(16.83 \%)$ \\
\hline 2. Does boiling water kill germs? & Yes (88\%) & No $(12 \%)$ \\
\hline 3. Human faeces has germs, and should be flushed. & Yes (71.4\%) & No $(28.6)$ \\
\hline 4. Water and food needs covering. & Yes (84\%) & No $(16 \%)$ \\
\hline 5. Waste items should not be thrown around the house or in open areas. & True (56\%) & False (44\%) \\
\hline 6. Stagnant water and dumping areas are home for mosquitoes. & True $(82.7 \%)$ & False (17.3\%) \\
\hline 7. Spraying pesticides will help control the spread of diseases. & True (77.1\%) & False $(22.9 \%)$ \\
\hline \multicolumn{3}{|l|}{ To assess the practices of personal hygiene } \\
\hline 8. Do you drink boiled water? & Yes (61.3\%) & No $(38.7 \%)$ \\
\hline 9. Do you wash hands before meal? & Yes (99.2\%) & No $(0.8 \%)$ \\
\hline 10. Do you wash hands after every meal? & Yes (100\%) & No $(0 \%)$ \\
\hline 11. Do you use a toilet inside your house? & Yes (99.1\%) & No $(0.9 \%)$ \\
\hline 12. Do you wash hands after going to the toilet? & Yes (100\%) & No $(0 \%)$ \\
\hline 13. Do you cover your mouth and nose during coughing and sneezing? & Yes (99.2\%) & No $(0.8 \%)$ \\
\hline 14. Do you wash hands after coughing and sneezing? & Yes (97.8\%) & No $(2.2 \%)$ \\
\hline 15. Do you use soap for washing hands? & Yes (98\%) & No $(2 \%)$ \\
\hline 16. Do you share your food and drinks even if you are sick? & No (10.3\%) & Yes (89.7\%) \\
\hline 17. Do you wear sandals all the time? & Yes (80.7\%) & No (19.3\%) \\
\hline 18. Do you take bath every day? & Yes (100\%) & No $(0 \%)$ \\
\hline 19. Do you use soap while bathing? & Yes (100\%) & No $(0 \%)$ \\
\hline 20. Do you brush twice, daily? & Yes (87.1\%) & No (12.9\%) \\
\hline 21. Do you use tooth brush and paste while brushing? & Yes (98.4\%) & No $(1.6 \%)$ \\
\hline 22. Do you cut your nails regularly? & Yes (86.5\%) & No (13.5\%) \\
\hline 23. Do you flush after using the toilet? & Yes (85.2\%) & No (14.8\%) \\
\hline 24. Do you dispose waste to municipal waste collectors? & Yes (48.7\%) & No (51.3\%) \\
\hline 25. Do you use mosquito nets, coils, repellants or mosquito bats at home? & Yes (99.2\%) & No $(0.8 \%)$ \\
\hline \multicolumn{3}{|l|}{ Attitude of children towards hygiene measures and control of communicable diseases. } \\
\hline 26. Personal hygiene and clean surroundings are important for healthy living & True (99.7\%) & False $(0.3 \%)$ \\
\hline 27. Sharing knowledge about healthy practices will lead to a disease free society? & Agree (99.1\%) & Disagree $(0.9 \%)$ \\
\hline 28. I am interested in increasing my knowledge about hygiene measures. & Yes (100\%) & No $(0 \%)$ \\
\hline
\end{tabular}


The sum of scores obtained by each student were added and graded asfollows:

\section{Table: 2}

\begin{tabular}{|l|c|}
\hline M ARKS OBTAINED & REM ARKS \\
\hline $24-28$ & Very good \\
\hline $19-23$ & Good \\
\hline $14-18$ & Average \\
\hline Below 14 & Poor \\
\hline
\end{tabular}

Score grades were predetermined to avoid any bias.

The survey was followed by education and motivation of students, addressing the need for awareness and better oral and personal hygiene measures through a health talk.

\section{Results}

The results of the survey were as follows:

Table: 3

\begin{tabular}{|l|c|c|c|c|c|}
\hline \multicolumn{6}{|l|}{ English medium } \\
\hline Grade & Below 14 & $14-18$ & $19-23$ & $24-28$ & Total \\
\hline $3^{\text {rd }}$ Std. & 2 & 15 & 59 & 40 & 116 \\
\hline $4^{\text {th }}$ Std. & 0 & 6 & 65 & 69 & 140 \\
\hline $5^{\text {th }}$ Std. & 0 & 0 & 25 & 117 & 142 \\
\hline $6^{\text {th }}$ Std. & 0 & 0 & 26 & 107 & 133 \\
\hline $7^{\text {th }}$ Std. & 0 & 0 & 26 & 45 & 071 \\
\hline Total & 2 & 21 & 201 & 378 & 602 \\
\hline
\end{tabular}

Total children surveyed $=602$

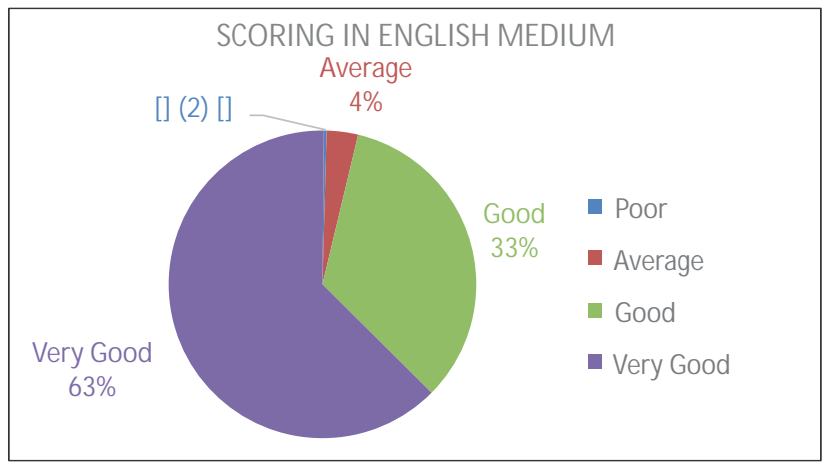

Children scoring poor results: 2 i.e. $0.3 \%$

Children scoring average results: 21 i.e. $3.48 \%$

Children scoring good results: 201 i.e. $33 \%$

Children scoring very good results: 378 i.e. $62.8 \%$

Table: 4

\begin{tabular}{|l|c|c|c|c|c|}
\hline \multicolumn{6}{|l|}{ Kannada medium } \\
\hline Grade & Below 14 & $14-18$ & $19-23$ & $24-28$ & Total \\
\hline $3^{\text {rd }}$ Std. & 3 & 17 & 25 & 10 & 55 \\
\hline $4^{\text {th }}$ Std. & 0 & 12 & 37 & 29 & 78 \\
\hline $5^{\text {th }}$ Std. & 5 & 16 & 31 & 15 & 67 \\
\hline $6^{\text {th }}$ Std. & 0 & 5 & 13 & 16 & 34 \\
\hline $7^{\text {th }}$ Std. & 0 & 0 & 19 & 23 & 42 \\
\hline Total & 8 & 50 & 125 & 93 & 276 \\
\hline
\end{tabular}

Total children surveyed $=276$
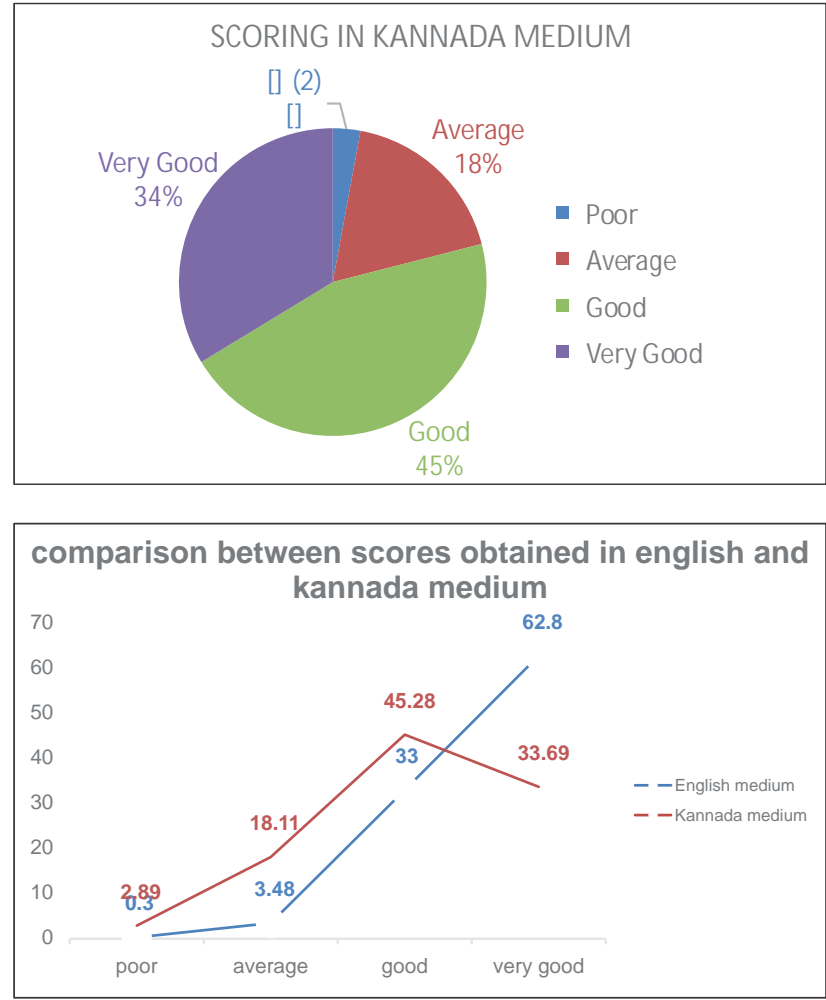

A comparison of data between the scores obtained by children in various grades among the English and Kannada medium students in this study points us towards a disparity in the knowledge, attitudes and practices of oral and personal hygiene between the two groups. An overall lower percentile scores were obtained by children from Kannada medium school.

\section{Discussion}

Personal hygiene can include a wide range of hygiene measures from hand and nail cleaning to whole-body cleaning and even to the items used for this purpose. ${ }^{1}$ There are several factors associated with the spread and control of communicable diseases, such as personal hygiene, sanitation and availability of safe drinking water, which are interlinked. Though there is explicit evidence for the effectiveness of measures such as basic hygiene practices in controlling communicable diseases, the scenario in many developing nations remain the same. Poor sanitary conditions, and basic personal hygiene behaviours, such as hand washing, are still not widely practised. ${ }^{2}$

In the present study, children scoring poor results were $0.3 \%$ in English medium school, when compared to $2.89 \%$ in Kannada medium school. Children scoring average results were $3.48 \%$ in English medium where as it was $18.11 \%$ in Kannada medium. This is in accordance with 
study conducted by Peltzer et al ${ }^{3}$ where, $22.4 \%$ of school children had reported sub-optimal oral and personal hygiene. Children showing good results were $33 \%$ in the English medium, whereas it was $45.28 \%$ in Kannada medium; and those showing very good results were $62.8 \%$ in English medium where as it was $36.9 \%$ in Kannada medium school.

When the two groups were compared, students from Kannada medium had suboptimal scores when compared to that of students from English medium. Considering the overall socioeconomic status of children going to English and Kannada medium schools respectively, it has been noted that children from the Kannada medium were generally of the lower socioeconomic status. Thus, the disparity among scores between the two groups could be attributed to the lack of awareness among children and their families, coming from a lower socioeconomic back ground.

Several limitations must be considered when interpreting our results. First, the students' self-reported behaviours may have resulted in over-reporting of their actual hygiene practices. Second, our study was limited to students in grades 3-7 and those who were present in school. Children absent due to illness or other circumstances were not included. Thus, the results from this study may not be generalized to all school children. Third, the cross-sectional study design makes determination of causality impossible. Lastly, there was no significant association between knowledge of proper hygiene and overall reported hygiene which may be attributed to the small sample size and possible over reporting of hygiene practices.

Our findings underscore the need for integrating hand washing and hygiene education programs in schools. Successful implementation of such programs in schools is more likely to contribute to reductions in morbidity and mortality associated with communicable diseases. ${ }^{3} \mathrm{~A}$ survey and analysis of literature done by Esray SA et al, ${ }^{5}$ had reported on the health benefits from optimal water supply and sanitation and concluded that there was a decrease in morbidity in areas with better water supply and sanitation.
Our survey tests the knowledge and practice of home hygiene among students so that the risk of the future generation can be assessed and appropriate interventions can be undertaken. This study targets two key issues that must be addressed when creating health and hygiene promotion programs. First, nearly half the students were unaware of the importance of having good knowledge on proper hygiene measures. To increase this, health clubscan be formed to teach students about disease causation and transmission, demonstrate proper hand washing techniques and hygiene practices, and to provide incentives for good personal hygiene. Education has the potential to significantly alter the behaviour patterns of students and can thereby lead to improved outlooks on hygiene. ${ }^{4}$

Second, much of hygiene practices are contingent upon availability of sufficient resources. Well-designed and welllocated hand washing facilities and latrines that include adequate amounts of soap and water, are essential in promoting hygiene. If hygiene intervention programs implement these two important factors-education and resources-the needs of students, and therein the society, can be better met and can thereby result in decreased risk of disease spread. The acquisition of personal hygiene practices into behavioural changes may become difficult with advancing age. This behaviour training for children begins in the family and continues in the school, which is represents their first community experience. ${ }^{5}$ Because students are in a close contact with one another in classrooms and during other activities, there is a high risk for the transmission of diseases, and by association, from school to the home environment. Hence personal cleaning and hygiene should be given optimum prioritization. ${ }^{1}$ The hygiene behaviour gained during childhood is translated to adulthood and directly affects the health of the individual in adulthood.

\section{Conclusion}

From our study, our findings conclude that students from English medium school had better oral and personal hygiene knowledge, attitude and practice scores than 
children from Kannada medium school. In line with this finding, we further recommend the need for intense campaigns for the promotion of good oral and personal

\section{References}

1. Arikan et al.Personal Hygiene Status among Primary School Students in an Urban Area in the west of TurkeyAmerican Journal of Research Communication. 2014; Vol 2(7):23-36.

2. Peltzer K, Pengpid S. Oral Health Behaviour and Social and Health Factors in University Students from 26 Low, Middle and High Income Countries. Int J Environ Res Public Health. 2014 December; 11(12): 12247-12260. Published online 2014 November 26. doi: 10.3390/ijerph111212247PM CID: PM C4276612.

3. Peltzer K, PengpidS.Oral and Hand Hygiene Behaviour and Risk Factors among In-School Adolescents in Four Southeast Asian Countries. Int J Environ Res Public Health. 2014 M arch; 11(3): 2780-2792. Published online $2014 \mathrm{March} 7$. doi: 10.3390/ijerph110302780PM CID: PM C3987003

4. Vivas A et al.Knowledge, Attitudes, and Practices (KAP) of Hygiene among School Children in Angolela, Ethiopia.JPrev Med Hyg. Author manuscript; available in PMC 2011 April 13.Published in final edited form as: J Prev Med Hyg. 2010 June; 51(2): 73-79. PMCID: PM C3075961

5. Esrey S. A et al.Effects of improved water supply and sanitation onascariasis, diarrhoea, dracunculiasis, hookworm infection, schistosomiasis, and trachoma. Bulletin of the World Health Organization.1991; 69 (5): 609-621. hygiene practices better aimed at the prevention of communicable diseases in local regional language medium schools in India. 